\title{
Fault Tolerant Of Three-Phase Inverter Fed Speed Sensorless Induction Motor Drive System
}

\author{
Z.M.S. El-Barbary \\ Department of Electrical Engineering, Kafrelsheikh University, Egypt \\ Department of Electrical Engineering, King Khalid University, Saudi Arabia \\ Tanta, Egypt \\ z_elbarbary@yahoo.com
}

\begin{abstract}
This paper proposes an algorithm for fault tolerance of three-phase inverter fed speed sensorless control of three- phase induction motor drive system. The fault tolerance of inverter when one switch is open or one leg of six-switch inverter is lost is considered. The control of the drive system is based on indirect rotor field oriented control theory. Also, the speed estimator is based on model reference adaptive system (using stator current and rotor flux as state variables for estimating the speed). The fault tolerant algorithm is able to adaptively change-over from six switch inverter to four switch inverter topologies when the fault is occurred; also, it makes a smooth transition of the motor speed, torque and current when changing over from faulty condition to new healthy status which is (Four-Switch Three-Phase Inverter (FSTPI) topology), thus, the Six Switch Three-Phase Inverter (SSTPI) topology (pre-fault status) almostly retained. The proposed algorithm is simulated by using the MATLAB/SIMULINK package. The obtained results from the simulation model demonstrate the performance enhancement and good validity of the faulttolerance control for speed sensorless induction motor drive system.
\end{abstract}

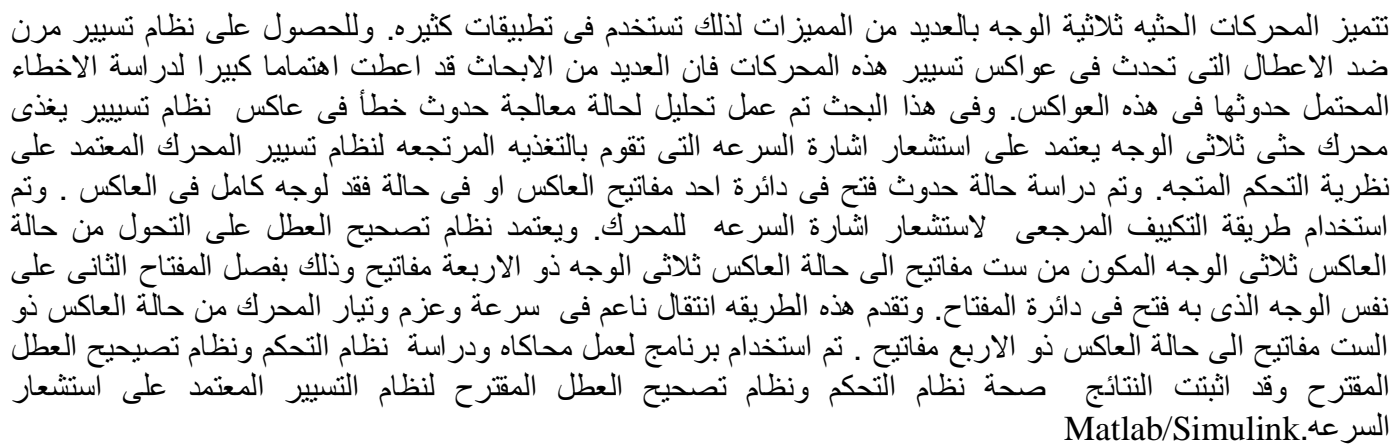

Keywords: Induction motor drive, Current control Voltage source inverter (CCVSI), Fault tolerant, four-switch three phase inverter (FSTPI).Insulated Gate Bipolar Transistor (IGBT).;

\section{INTRODUCTION}

Three phase induction motors have been the workhorse for industrial and manufacturing processes. The energization of such motors in these processes and applications can be achieved through the following ways: (1) direct on-the-line starting, (2) soft-starting, and (3) adjustable-speed drive (ASD) control. With the development of power electronics and digital signal processor, induction motors are predominantly fed from pulse width modulation (PWM) inverter, so, ASDs are widely adopted in many industrial applications. In fact, the main reasons for their adoption in these applications are owed to the robust control and high ASDs offers high performance like soft starting, soft stop, speed reversal, breaking and many types of speed control methods as compared to soft starters. Nevertheless, soft starters are a low cost means in comparison to ASDs if the application does not require to speedtorque control. The reliability of electrical drives is a big aim and has not been resolved because the power electronic devices and control circuit are fail part of the inverter. [1]. The faults sources in the drives are, the power converter circuits (about 38 percent) ,control circuits (about 53 percent ) and external auxiliaries(about 9 percent) [2]. There two types of power semiconductor switches' faults of inverters. [3-6]. the first type is transistor short-circuit switchfault, this fault leads to catastrophic failure of the 
inverter if the other transistor of the same inverter leg is turned-on, this resulting in a direct short-circuit of the dc-bus link. To prevent the short circuit fault, it is necessary to minimize possible elapsed time after the fault occurred [7]. The other type of faults is open circuit fault of transistor. The drive may be operating with open circuit fault of any transistor, but with much inferior of performance, the electromechanical torque is affected and pulsating because the motor currents are asymmetric due to one phase's current is unipolar. Hence, a drive fault diagnostic system determines the type; hence the fault tolerant takes appropriate correction action of the fault.

There are two ways to test the drive fault, experimentally in the actual motor drives and another is fault simulation. [8-11].

This paper presents a fault tolerant control of six switch inverter fed speed sensorless control of three phase induction motor drive. The fault tolerant control depends on transition from six to four switch inverter algorithms. The transition executed by one of the extra switches as shown in Figure 1. The extra switch receives the fault tolerant signal from control system, and connects the motor's phase that it lost to the mid- point of a dc capacitor bank. A simulation results are carried out using. MATLAB/SIMULINK package. The proposed system of fault tolerant of inverter introduces a good behavior with speed sensorless indirect rotor field oriented control of induction motor drive.

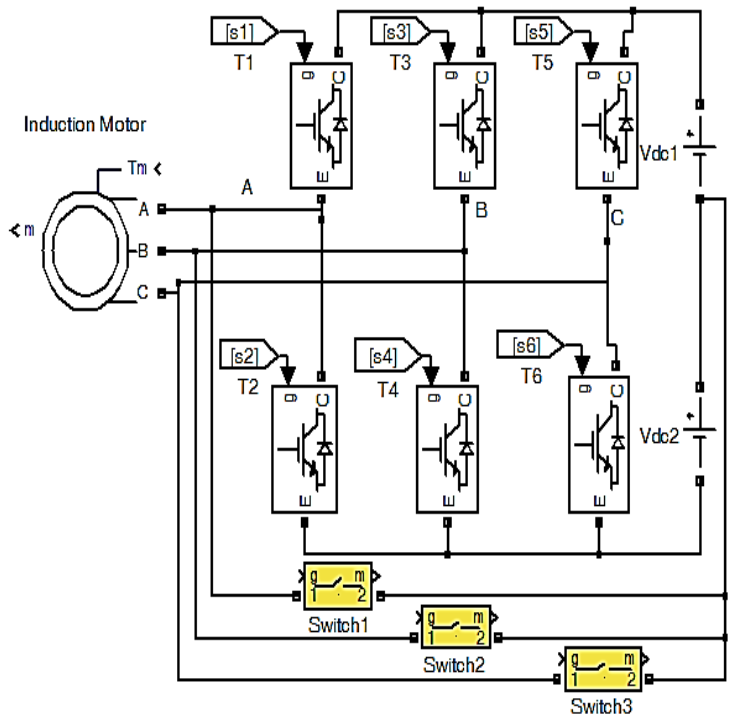

Fig.1 Six-switch inverter topology with extra switches

\section{SYSTEM DESCRIPTION}

The proposed system intended for performance analysis of sensorless indirect rotor field oriented control of induction motor drive is shown in Fig. 2. The field oriented control (FOC) block receives the torque command $\mathrm{T}^{*}$, obtained from the speed PI- controller, while the flux command $\lambda_{\mathrm{dr}}^{*}$ is maintained constant. The field oriented control block performs the slip calculation and generates the current command components $\mathrm{i}_{\mathrm{qs}}^{\mathrm{e}}$ and $\mathrm{i}_{\mathrm{ds}}^{\mathrm{e}}$ in a rotating reference frame. These components are further manipulated by axes transformations to obtain the abc current command components $i_{a r}, i_{b r}$, and $i_{c r}$. The axes transformations used for the present system are expressed as follows;

$\left[\begin{array}{c}i_{q s}^{s^{*}} \\ i_{d s}^{s^{*}}\end{array}\right]=\left[\begin{array}{cc}\cos \theta_{s} & \sin \theta_{s} \\ \sin \theta_{s} & \cos \theta_{s}\end{array}\right] *\left[\begin{array}{c}i_{q s}^{e^{*}} \\ i_{d s}^{e^{*}}\end{array}\right]$

Where $\theta_{\mathrm{s}}$ represents the sum of the slip and rotor angles.

$$
q d s \rightarrow a b c\left\{\begin{array}{l}
i_{a s}^{s^{*}}=i_{q s}^{s^{*}} \\
i_{b s}^{s^{*}}=-\frac{1}{2} i_{q s}^{s^{*}}-\frac{\sqrt{3}}{2} i_{d s}^{s^{*}} \\
i_{c s}^{s^{*}}=-\frac{1}{2} i_{q s}^{s^{*}}+\frac{\sqrt{3}}{2} i_{d s}^{s^{*}}
\end{array}\right\}
$$

\section{MATHEMATICAL MODEL}

This section presents the mathematical model of the induction motor drive system, shown in fig. (1) to revise the recital of the scheme at diverse working settings. In addition a detailed analysis of a fault tolerant of inverter fed speed senseless drive.

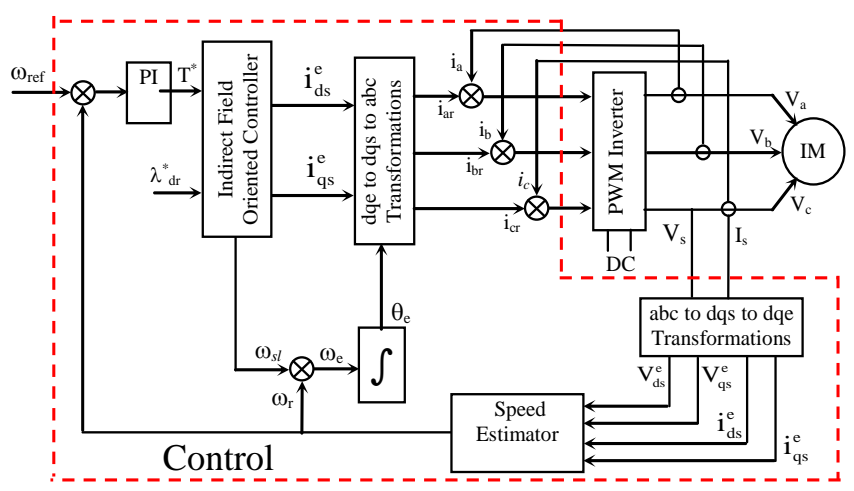

Fig. 2 Block Diagram of the Proposed Speed Sensorless Control System

\section{A. Induction Motor Model}

The dynamic model of squirrel-cage induction motor in synchronous reference frame is expressed as follows; 


$$
\left[\begin{array}{c}
V_{\text {que }}^{e} \\
V_{d i e}^{e} \\
0 \\
0
\end{array}\right]=\left[\begin{array}{cccc}
R_{s}+p L_{\sigma} & \omega_{e} L_{\sigma} & p \frac{L_{m}}{L_{r}} & \omega_{e} \frac{L_{m}}{L_{r}} \\
-\omega_{e} L_{\sigma} & R_{s}+p L_{\sigma} & -\omega_{e} \frac{L_{m}}{L_{r}} & p \frac{L_{m}}{L_{r}} \\
-R_{r} L_{m} & 0 & R_{r}+p L_{\sigma} & \left(\omega_{e}-\omega_{r}\right) L_{m} \\
0 & -R_{r} L_{m} & -\left(\omega_{e}-\omega_{r}\right) L_{m} & R_{r}+p L_{\sigma}
\end{array}\right]\left[\begin{array}{c}
I_{q s}^{e} \\
I_{d s}^{e} \\
\lambda_{q r}^{e} \\
\lambda_{d r}^{e}
\end{array}\right]
$$

The electromechanical equation is also given by;

$T_{e}-T_{L}=J \frac{d \omega_{r}}{d t}+B \omega_{r}$

Where, the electromagnetic torque is expressed as:

$T_{e}=\frac{3}{2} \frac{p}{2} \cdot \frac{L_{m}}{L_{r}}\left(I_{q s}^{e} \lambda_{d r}^{e}-I_{d s}^{e} \lambda_{q r}^{e}\right)$

Equation (3) denotes that the torque can initially proportional to the quadrature component of the stator current $\left(I_{q S}^{e}\right)$ if the $\mathrm{q}^{\mathrm{e}}$-axis component of the flux becomes zero $\left(\mathrm{d}^{\mathrm{e}}\right.$-axis is aligned with the rotor flux axis), and the $\mathrm{d}^{\mathrm{e}}$-axis component $\left(\lambda_{d r}^{e}\right)$ is kept constant. This is the philosophy of the vector control technique. In accordance, Eq.(3) is linearized as :

$T_{e}=K_{t}\left|\lambda_{d r}^{e}\right| I_{q S}^{e}$

This equation is similar to that of the separately excited dc motor. The angular slip frequency command $\left(\omega_{s l}^{*}\right)$ is calculated as follow:

$\omega_{s l}^{*}=\frac{L_{m}}{\tau_{r}^{*}} \cdot \frac{I_{q s}^{e^{*}}}{\lambda_{d r}^{e^{*}}}$

Also from Eq. (4)

$I_{d s}^{e^{*}}=\frac{1}{L_{m}}\left(1+\tau_{r}^{*} p\right) \lambda_{d r}^{e^{*}}$

Angular frequency is obtained as follows,

$\omega_{e}=\omega_{r}+\omega_{s l}$

(7)

$\theta_{e}=\int \omega_{e} \cdot d t$

(8)

The torque producing current component is calculated from:

$I_{q S}^{e^{*}}=\frac{1}{k_{t}} \frac{\left(\omega_{r}^{*}-\omega_{r}\right)}{\lambda_{d r}^{e^{*}}} \frac{K_{p s}\left[1+\tau_{C S} S\right]}{\tau_{C S} S}$

(9)

Where $\omega_{r}$ is the rotor speed which will be obtained as in the following section.

\section{B. MRAS Based Speed Estimation}

Model Reference Adaptive Systems (MRAS) techniques are applied in order to estimate rotor speed. This technique is based on the comparison between the outputs of two estimators. The estimator that does not involve the quantity to be estimated (the rotor speed $\omega_{r}$ ) is considered as the induction motor voltage model. This model is considered to be the reference model $(\mathrm{RM})$. And the other model is the current model, derived from the rotor equation, this model is considered to be the adjustable model (AM). The error between the estimated quantities of the two models is used to drive a suitable adaptation mechanism which generates the estimated rotor speed; $\left(\omega_{\mathrm{r}}\right)$ to be used in the current model is [12]. In this paper, the observer depends on the MRAS and speed observer based on stator current and rotor flux as shown in Fig. 3. The stator current is represented as:

$$
\begin{aligned}
& i_{d s}=\frac{1}{L_{m}}\left[\lambda_{d r}+\omega_{r} T_{r} \lambda_{q r}+T_{r} p \lambda_{d r}\right] \\
& i_{q s}=\frac{1}{L_{m}}\left[\lambda_{q r}-\omega_{r} T_{r} \lambda_{d r}+T_{r} p \lambda_{q r}\right]
\end{aligned}
$$

Using the above Equations, the stator current is estimated as,

$$
\begin{aligned}
& \hat{i}_{d s}=\frac{1}{L_{m}}\left[\lambda_{d r}+\widehat{\omega}_{r} T_{r} \lambda_{q r}+T_{r} p \lambda_{d r}\right] \\
& \hat{i}_{q s}=\frac{1}{L_{m}}\left[\lambda_{q r}-\widehat{\omega}_{r} T_{r} \lambda_{d r}+T_{r} p \lambda_{q r}\right]
\end{aligned}
$$

The difference in the stator current is obtained as

$$
\begin{aligned}
& i_{d s}-\hat{i}_{d s}=\frac{T_{r}}{L_{m}} \lambda_{q r}\left[\omega_{r}-\widehat{\omega}_{r}\right] \\
& \hat{i}_{q s}-i_{q s}=\frac{T_{r}}{L_{m}} \lambda_{d r}\left[\omega_{r}-\widehat{\omega}_{r}\right]
\end{aligned}
$$

Equation (12) may be rewritten as:

$$
\begin{aligned}
& \left(i_{d s}-\hat{i}_{d s}\right) \lambda_{q r}=\frac{T_{r}}{L_{m}} \lambda_{q r}^{2}\left[\omega_{r}-\widehat{\omega}_{r}\right] \\
& \left(\hat{i}_{q s}-i_{q s}\right) \lambda_{d r}=\frac{T_{r}}{L_{m}} \lambda_{d r}\left[\omega_{r}-\widehat{\omega}_{r}\right]
\end{aligned}
$$

Since the stator current error is represented as a function of estimated speed, an adaptive flux observer can be constructed from the machine model equation. The model outputs are the estimated values of the stator current vector $\hat{i}_{S}$ and the rotor flux linkage vector $\hat{\lambda}_{\mathrm{r}}$. From Eqn. (13),

$$
\left(i_{d s}-\hat{i}_{d s}\right) \lambda_{q r}+\left(\hat{i}_{q s}-i_{q s}\right) \lambda_{d r}=\frac{T_{r}}{L_{m}}\left(2_{q r}+2_{d r}\right)\left[\omega_{r}-\widehat{\omega}_{r}\right]
$$

Hence, the error of the rotor speed is obtained as follows:

$$
\begin{aligned}
& \omega_{r}-\widehat{\omega}_{r}=\left[\left(i_{d s}-\hat{i}_{d s}\right) \lambda_{q r}-\left(i_{q s}-\hat{i}_{q s}\right) \lambda_{d r}\right] / K \\
& \text { where } \quad K=\frac{T_{r}}{L_{m}}\left(\lambda_{q r}^{2}+\lambda_{d r}^{2}\right)
\end{aligned}
$$

The right hand term seems as the term of speed calculation from adaptive observer, so the speed can be calculated from the following equation, Also Fig. 2 shows this method of speed estimation . 


$$
\begin{array}{r}
\widehat{\omega}_{r}=\frac{1}{K}\left[\left(K_{p}\left(i_{d s}-\hat{i}_{d s}\right) \lambda_{q r}-\left(i_{q s}-\hat{i}_{q s}\right) \lambda_{d r}\right)+\right. \\
\left.\left(K_{I} \int\left(i_{d s}-\hat{i}_{d s}\right) \lambda_{q r}-\left(i_{q s}-\hat{i}_{q s}\right) \lambda_{d r}\right)\right]
\end{array}
$$

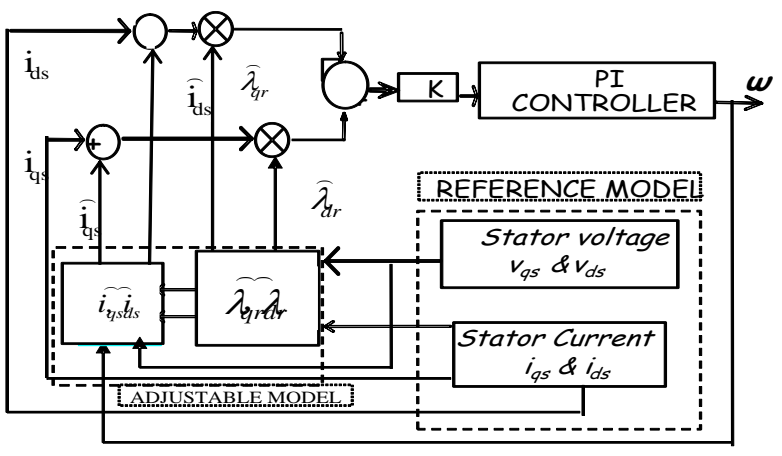

Fig.3 MRAS speed estimation scheme

\section{Current Control Voltage Source Inverter}

A three-phase inverter consists of a six switch (T1 to T6) inverter as shown in fig. 1. The DC link capacitors fed from three phase uncontrolled rectifier The two- level current control of the six-switch bridge inverter is used to control the load current by forcing it to follow a reference one. This is achieved by the switching action of the inverter to keep the current within the hysteresis band. The load currents are sensed and compared with respective command currents using two independent hysteresis comparators .The output signal of the comparators are used to activate the inverter power switches. This controller is simple and provides excellent dynamic performance.

$\begin{array}{llllr}i_{\text {ref }} & & =i_{\text {max }} & & \sin (\omega t) \\ (17) & & & & \\ i_{u p}= & i_{\text {ref }} & & + & H \\ (18) & & & & \\ i_{l o} & =i_{\text {ref }} & - & H\end{array}$

(19)

Where, $i_{\text {ref }}$ is the reference current (may be $i_{a r}, i_{b r}$ or $\mathrm{i}_{\mathrm{cr}}$ ), $\mathrm{i}_{\text {up }}$ is the upper band, $\mathrm{i}_{\mathrm{lo}}$ is the lower band and $\mathrm{H}$ is the hysteresis band. For $i_{a r}>0.0$ : if $i_{a}>i_{\text {up }}$, then $\mathrm{NA}=0$, this means that the inverter output voltage switches to negative in order to reduce the line current. In the same manner if $i_{a}<i_{\text {lo }}$, then. $N A=1$, where the inverter output voltage switches to positive in order to increase the line current. The same sequence is followed for phase b and c. Hence, the control logic for phases are given as follow: For $i_{a r}>0.0$ : if $i_{a}>i_{u p}$, then NA=0, else if $i_{a}<i_{l o}$ then NA=1, For $i_{\text {ar }}<0.0$ : if $i_{a}<i_{\text {up }}$, then $N A 1=1$, else if $i_{a}>i_{\text {lo }}$ then $\mathrm{NA} 1=0$, the switches of each leg are controlled complementary (i.e. NA1 $=1-\mathrm{NA}$ ), and the same logic generation for phases $\mathrm{B}$ and $\mathrm{C}$.

Hence, The modulated phases voltages of six switch inverter are introduced as a function of switching logic NA, NA1, NB ,NB1 and NC,NC1 of power switches by the following relations:

$$
\left[\begin{array}{l}
V_{a} \\
V_{b} \\
V_{C}
\end{array}\right]=\frac{V_{d c}}{3}\left[\begin{array}{ccc}
2 & -1 & -1 \\
-1 & 2 & -1 \\
-1 & -1 & 2
\end{array}\right]\left[\begin{array}{l}
N A \\
N B \\
N C
\end{array}\right]
$$

\section{DC CuRRent Fault DEteCtion Method}

This method of the inverter fault detection depends on which transistor is open. Opened switch does not pass any current, the phase current can only be positive or negative and behave characteristically, Also, the dc current component appears, whereas these component of dc currents disappear in healthy condition.

The dc current fault detection method states is as follows, using the Park's Vector transformation in ( $\alpha$ $\beta$ ) axis, equations (20) and (21) are explained the currents yields to trajectories as displayed in figure 4 .

$$
\begin{gathered}
I_{\alpha}=I_{a} \\
I_{\beta}=\frac{I_{b}-I_{c}}{\sqrt{3}}
\end{gathered}
$$

The direct component is used as diagnostic variable and calculated as follows;

$\mu_{v}=\frac{1}{N} \sum_{l}^{N} I_{v}(k \tau)$

The resulting space vector can be described by magnitude and angle as follows;

$\left|\mu_{v}\right|=\sqrt{\mu_{\alpha}^{2}+\mu_{\beta}^{2}}$

$\arg (\mu)=\arctan \left(\frac{\mu_{\beta}}{\mu_{\alpha}}\right)$

$v \in[\alpha, \beta]$

In healthy condition (no fault) the average value of current is zero and the current space vector runs in a circle. To resist noise and transients; if the magnitude exceeds a certain threshold fault is detected. And the opened switch is determined using table (I). The method developed by Abramik [13] also uses the direct component, $\gamma$ of the phase currents, which is calculated by averaging over one period (22).To obtain a diagnostic variable that is independent of the actual load, the first order harmonic coefficients of the phase currents are computed by means of a DFT, equations (26), (27) Dividing the direct component by the calculated DFT coefficient provides the diagnostic variable $\gamma_{\mathrm{v}}$, this is done for all three phases (eqn. 25).

$$
\gamma_{v}=\frac{\mu_{v}}{\sqrt{a_{1, v}^{2}+b_{1, v}^{2}}}
$$


$a_{1, v}=\frac{2}{N} \sum_{K=i-N+1}^{i} I_{v}(k \tau) \cos \left(\frac{2 \pi k}{N}\right)$

$b_{1, v}=\frac{2}{N} \sum_{K=i-N+1}^{i} I_{v}(k \tau) \sin \left(\frac{2 \pi k}{N}\right)$

$d_{1, i}=\left\{\begin{array}{l}1: \gamma_{i} \succ 0 \\ 0: \gamma_{i} \leq 0\end{array}\right.$

(28)

$d_{2, i}=\left\{\begin{array}{l}1:\left|\gamma_{i}\right| \succ 0.45 \\ 0:\left|\gamma_{i}\right| \leq 0.45\end{array}\right.$

(29)

$v \in[a, b, c]$

(30)

The decision on whether there is a fault and which transistor is faulty is based on table (I) with equations (28) and (29), [13].
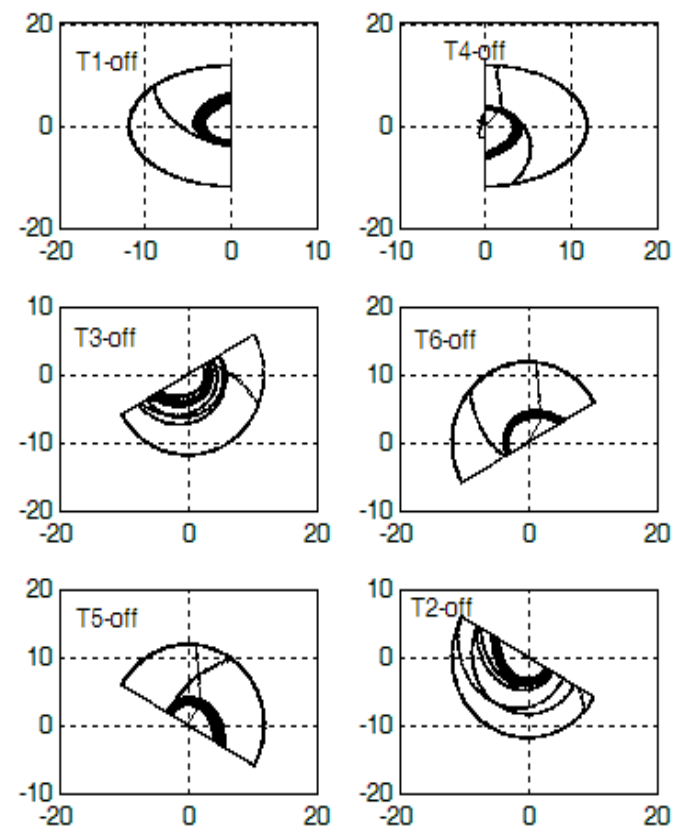

Fig. (4) Trajectory of phase currents in Park's Vector

TABL (I): LOCALIZATION OF FAULT WTHN ORMALIZDECD CURRENT

\begin{tabular}{|c|c|c|c|c|c|c|}
\hline Transistor & $\mathrm{d}_{1, \mathrm{a}}$ & $\mathrm{d}_{1, \mathrm{~b}}$ & $\mathrm{~d}_{1, \mathrm{c}}$ & $\mathrm{d}_{2, \mathrm{a}}$ & $\mathrm{d}_{2, \mathrm{~b}}$ & $\mathrm{~d}_{2, \mathrm{c}}$ \\
\hline $\mathrm{T} 1$ & 1 & 0 & 0 & 1 & 0 & 0 \\
\hline $\mathrm{T} 2$ & 1 & 0 & 1 & 0 & 1 & 0 \\
\hline $\mathrm{T} 3$ & 0 & 0 & 1 & 0 & 0 & 1 \\
\hline $\mathrm{T} 4$ & 0 & 1 & 1 & 1 & 0 & 0 \\
\hline $\mathrm{T} 5$ & 1 & 0 & 1 & 0 & 1 & 0 \\
\hline T6 & 1 & 1 & 0 & 0 & 0 & 1 \\
\hline
\end{tabular}

\section{$V$. FOUR-SWITCH INVERTER TOPOLOGY}

When the fault occurs, the fault detection system forces the modulated phase voltages to operate as four-switch inverter by opening the other switch in the faulty leg as shown in figure (5), and the phase voltages become:

$$
\begin{aligned}
& V_{a}=\frac{E_{d c}}{3}(4 N A+2 N B-1) \\
& V_{b}=\frac{E_{d c}}{3}(-2 N A+4 N B-1) \\
& V_{c}=\frac{E_{d c}}{3}(-2 N A-2 N B+2)
\end{aligned}
$$

During fault as a function of switching logic NA, NA1 and NB, NB1, wherars phase C is faulty. The phase voltage in I matrix form,

$$
\left[\begin{array}{l}
V_{a} \\
V_{b} \\
V_{c}
\end{array}\right]=\frac{E_{d c}}{3}\left[\begin{array}{ccc}
4 & 2 & -1 \\
-2 & 4 & -1 \\
-2 & -2 & 2
\end{array}\right]\left[\begin{array}{c}
N A \\
N B \\
1
\end{array}\right]
$$

Also, it will be assumed that a stiff voltage is available across the two dc-link capacitors [14].

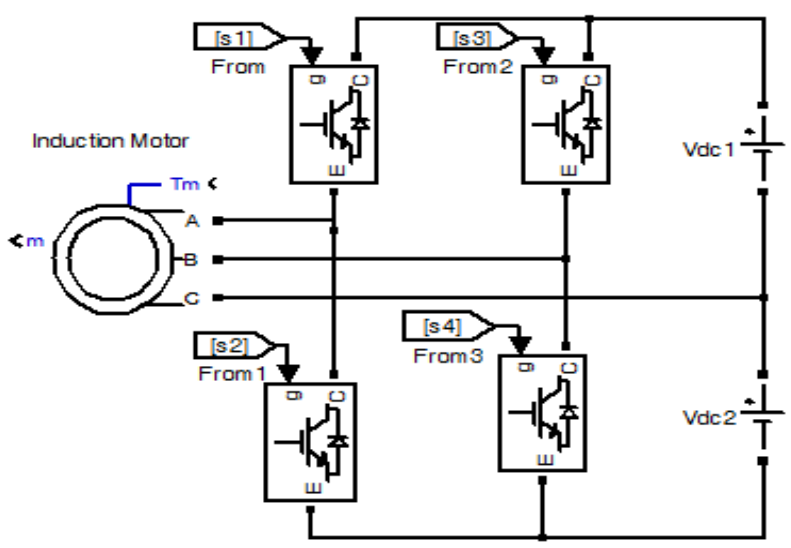

Fig. 5 Four-switch inverter topology

\section{RESULTS AND DISCUSSION}

The proposed control system shown in Fig. (1) is simulated using the general purpose simulation package MATLAB/SIMULINK [15]. Simulation results are presented to show the effectiveness of the proposed scheme at different operating conditions. These results are classified into two case studies; the first represents system response with fault condition while the second represents the system response with fault tolerance. In the First case study, the system starts and runs normally in six-switch inverter algorithm with a load torque of (3N.m) and speed reference of $100 \mathrm{rad} / \mathrm{sec}$. At $\mathrm{t}=0.75 \mathrm{~s}$, the fault is occurred and the leg A is faulty. System continues to run by FOC six-switch inverter. The stator currents, dc components of those currents, electromagnetic torque are measured. Also, the motor speed is measured and estimated. In the second case study, the fault tolerant system has been applied for both one switch opening and two switches opening faults. If one switch is opened the control system disconnect the other switch in the same leg also, by sending a fault tolerance signal command to an extra switch, the switch connect the related motor terminal to the 
mid-point of dc link capacitors, finally, the FOC system operates with four switch inverter algorithm.

Figures 6 and 7, present the motor response in the previous cases. Figure 6 shows that there is obvious component superimposed on the motor currents related to phases a and b. Figure 7 shows that a dc component have been vanished due to fault tolerance control action. Figures 8 shows the stator current in $\alpha-\beta$ axis system under fault condition, where, figure 9 shows the same current components under fault tolerance condition, it is noted that the distortion in the current wave form when the system transition from fault to fault tolerant conditions is eliminated . Fig. 10 show the measured and estimated speed signals and electromagnetic torque respectively in fault case its noted that the estimated speed of motor and electromagnetic torque signals is more affected than the measured speed because it depend on the motor current. Whereas, fig. 11 shows the same results when the fault tolerance control system is applied, its noted also the electromagnetic torque in the region after fault tolerant (four switch inverter) is more rippled than before fault (six-switch inverter).
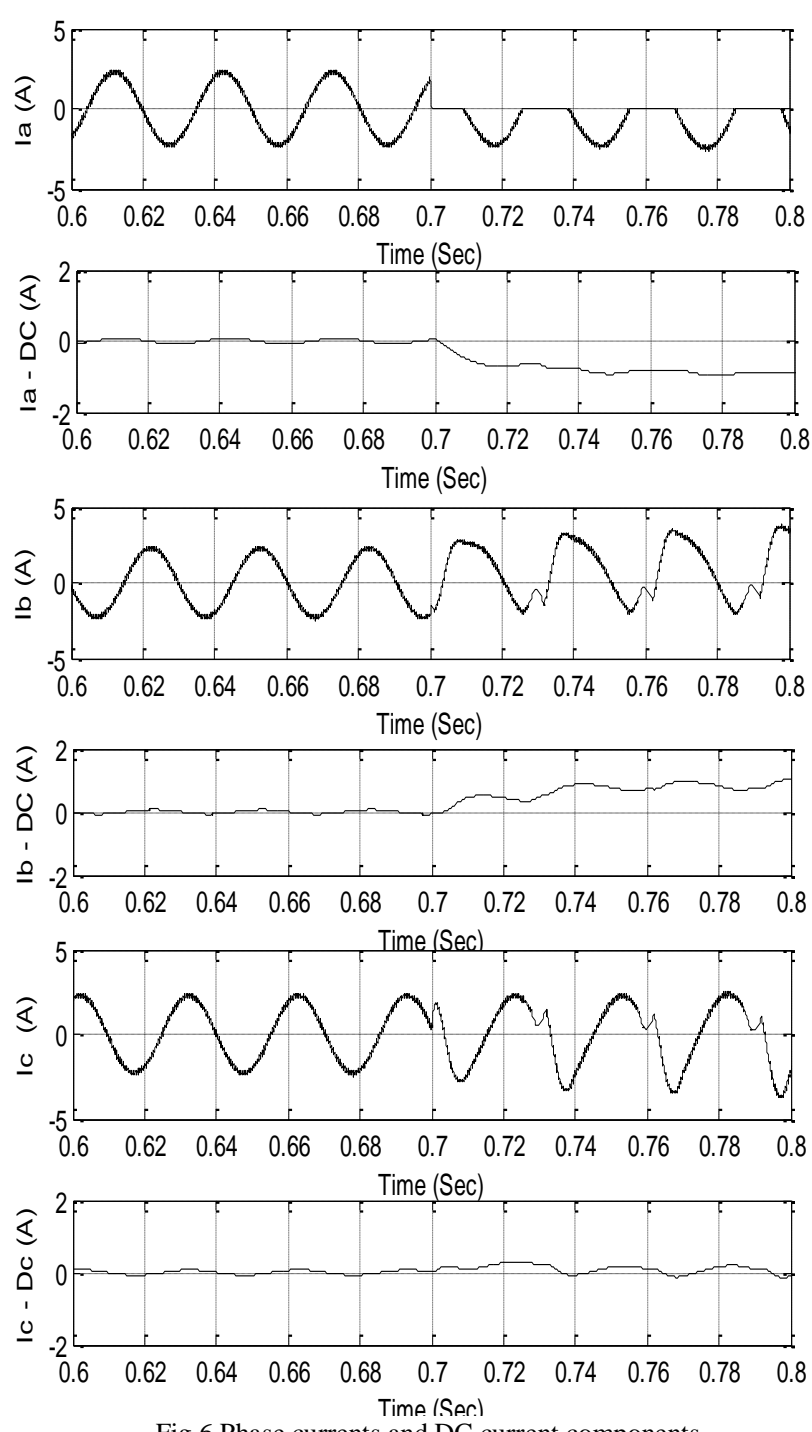

Fig.6 Phase currents and DC current components of the system under fault condition
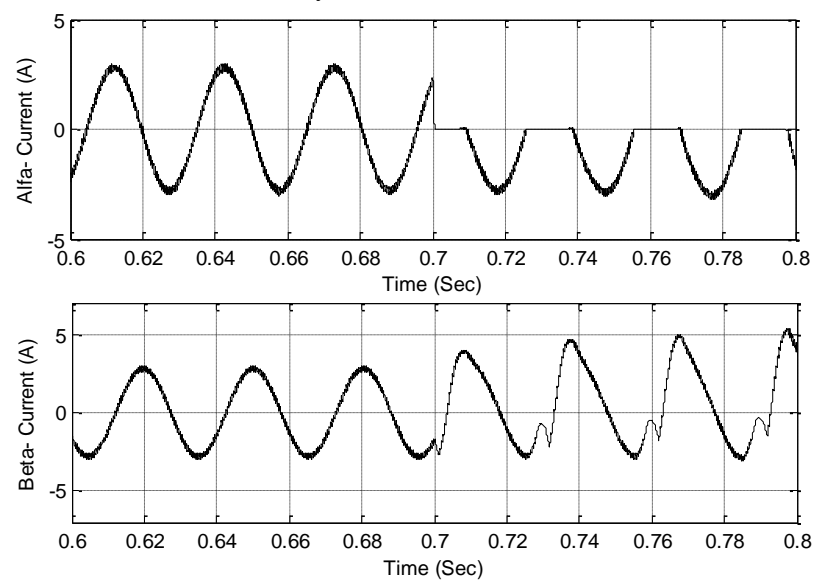

Fig.8 ( $\alpha$ and $\beta$ ) currents under fault condition 

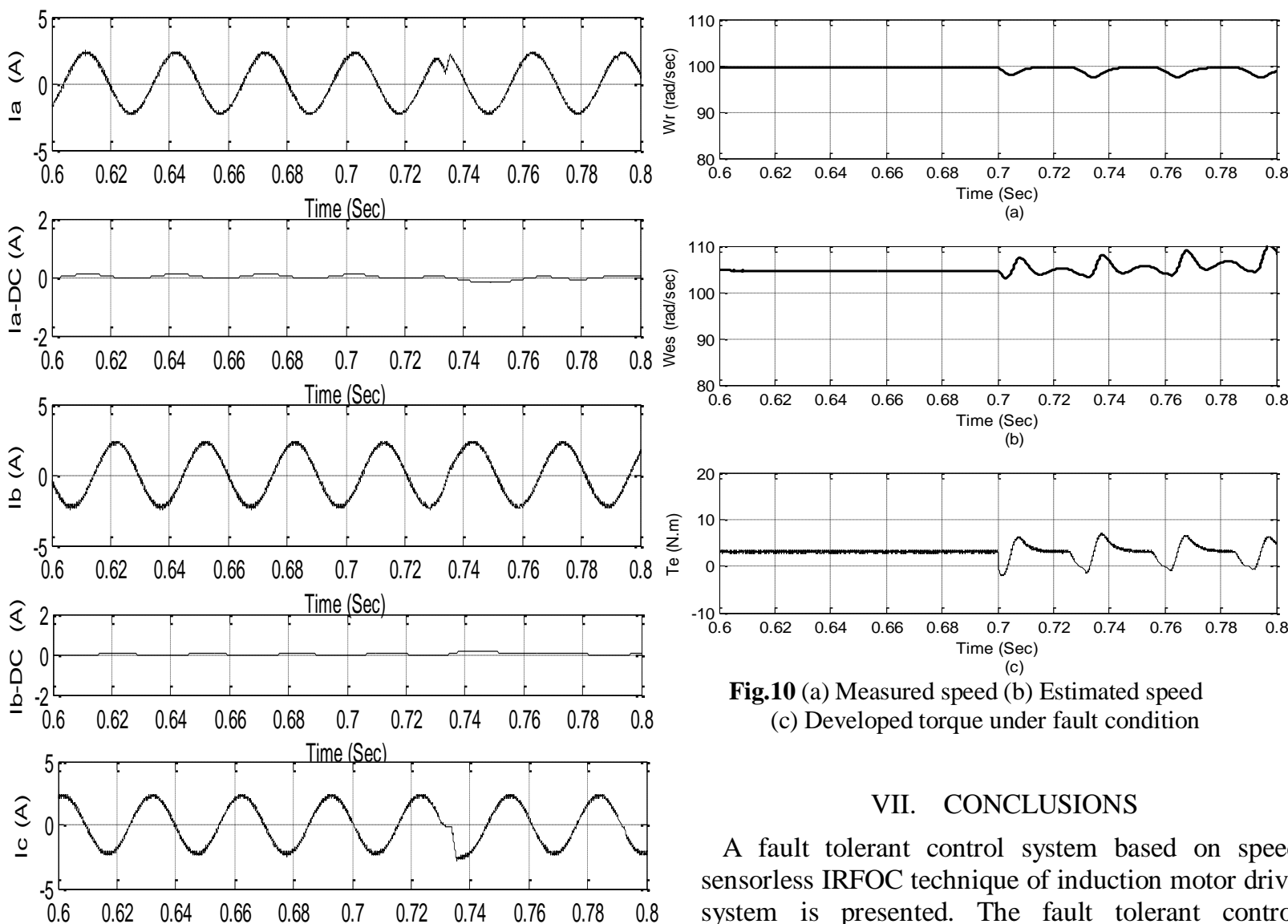

Fig.10 (a) Measured speed (b) Estimated speed (c) Developed torque under fault condition

\section{CONCLUSIONS}

A fault tolerant control system based on speed sensorless IRFOC technique of induction motor drive system is presented. The fault tolerant control includes two main algorithms; one for six-switch and the other for four switch inverter; operating in parallel. The control system changes-over between the mentioned algorithms when the fault occurs. The proposed control algorithm is verified by using a $1.5 \mathrm{~kW} / 380 \mathrm{~V} / 50 \mathrm{~Hz}$ induction motor simulated with SIMULINK/MATLAB. The results obtained from simulation show the effectiveness of the proposed fault tolerant system with speed sensorless induction motor drive, Also gives good behaviors similar to healthy condition with six switch inverter.

\section{REFERENCES}

[1] M. E. H. Benbouzid, "Bibliography on induction motors faults detection and diagnosis," IEEE Trans. Energy Conversion, vol. 14, pp. 1065 1074, Dec. 1999

[2] D. Kastha and B. K. Bose, "Investigation of fault modes of voltage fed inverter system for induction motor drive ," IEEE Trans. Ind. Application., vol. 30, pp. 426-433, July 1994.

[3] B. A. Welchko, T. A. Lipo, T. M. Jahns, and S E. Schulz, "Fault tolerant three-phase ac motor drive topologies: A comparison of features, cost, and limitations," IEEE Transactions on Power Electronics, Vol. 19, No. 4, pp. 1108-1116, Jul. 2004.

[4] R. Spée and A. K. Wallace, "Remedial strategies for brushless dc drive failures," IEEE

Transactions on Industry Applications, Vol. 26, No. 2, pp. 259-266, Mar./Apr. 1990. 
[5] A. M. S. Mendes, X. M. Lopez-Fernandez, and A. J. M. Cardoso, "Thermal behavior of a threephase induction motor fed by a fault-tolerant voltage source inverter," IEEE Transactions on Industry Applications, Vol. 43, No. 3, pp. 724730, May/Jun. 2007.

[6] B. A. Welchko, J. Wai, T. M. Jahns, and T. A. Lipo, "Magnet-flux-nulling control of interior PM machine
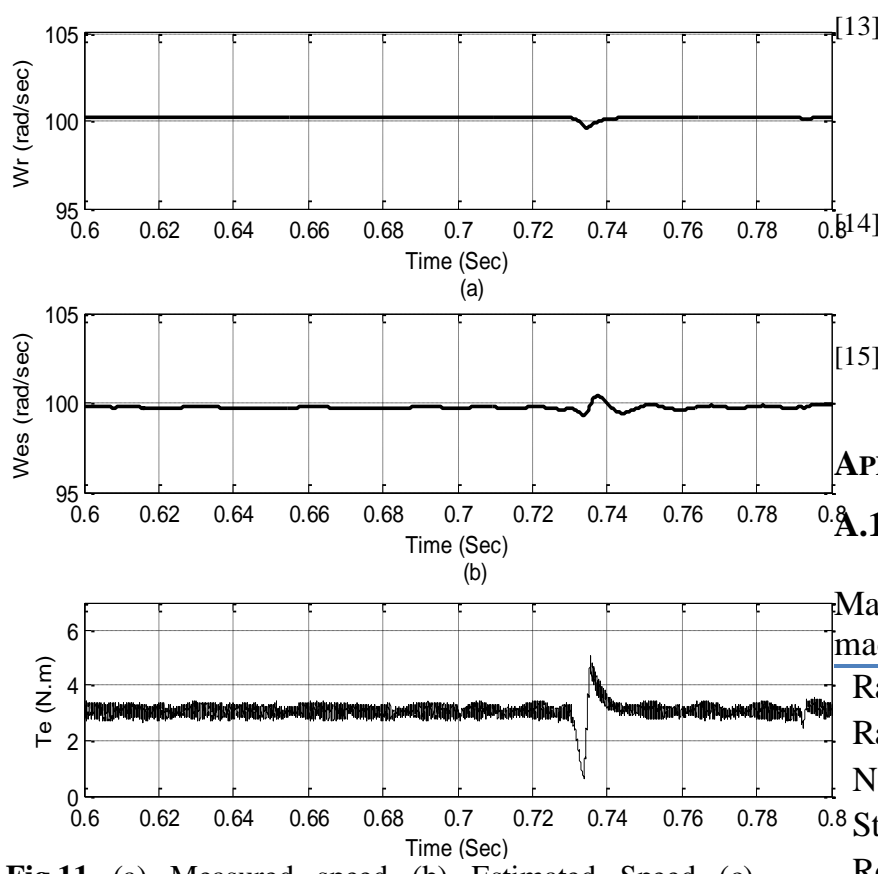

Fig.11 (a) Measured speed (b) Estimated Speed (c) Developed Torque under fault tolerant control

drives for improved steady-state response to short-circuit faults," IEEE Transactions on Industry Applications, Vol. 42, No. 1, pp. 113120, Jan./Feb. 2006.

[7] M. E. H. Benbouzid et aI., "A loss-minimization DTC scheme for EV induction motors," in Proc. IEEE VPPC, Chicago, IL, Sep. 2005, pp. 315321.

[8] C. Gerada, M. Sumner, J. Arellano-Padilla Sch. "Investigation of induction machine phase open circuit faults using a simplified equivalent circuit model", Electrical. \& Electron. Eng., Univ. of Nottingham, Nottingham 10/2008;

[9] C. C. Chan, "The state of the art of electric and hybrid vehicles,"Proc. IEEE, vol. 90, no. 2, pp.247-275, Feb.2002.

[10] Brian A. Welchko, Thomas A. Lipo, Thomas M. Jahns, and Steven E. Schulz, "Fault tolerant three-phase AC motor drive topologies: A comparison of features, cost, and limitations," IEEE Trans. Power Electronics., Vol. 19, NO. 4, July 2004.

[11] M. E. H. Benbouzid, D. Diallo, and M. Zeraoulia, "Advanced fault tolerant control of induction-motor drives for $\mathrm{EV} / \mathrm{HEV}$ traction applications: from conventional to modern and intelligent control techniques," IEEE Trans. Vehicular Technology., Vol. 56, NO. 2, March 2007.

[12] Chul-Woo Park, Woo-Hyen Kwon "Simple and robust speed sensorless vector control of induction motor using stator current based MRAC" Electric Power Systems Research 71, pp. 257-266, 2004.

[13] S. Abramik, W. Sleszynski, J. Nicrnanski, H. Piquet. A Diagnostic Merhod fir \&-Line Foul1 Detection and Localizarion in VSI-Fed AC Driver, EPE 2003, 10th Europcan Confercncc on Powcr Electronicsand Applicatians.Toulousc, France. CD-ROM papcr

4] M. Monfared, H. Rastegar, H. M. Kojabadi, "Overview of modulation techniques for the four-switch converter topology," PECon 08, 1-3 Dec 2008, Johor Baharu, Malaysia.

[15] MATLAB/SIMULINK Toolbox User's Guide, The Mathworks Inc., Natick, MA, USA, May 1998.

\section{APPENDICES}

\section{Å.1. Motor Data and Parameters:}

Machine parameters of the applied induction machine

\begin{tabular}{ll}
\hline Rated power & $1.1 \mathrm{kw}$ \\
Rated load torque & $7.5 \mathrm{~N} . \mathrm{m}$. \\
No. of poles & 4 \\
0.8 Stator resistance & $7.4826 \mathrm{ohm}$ \\
Rotor resistance & $3.6840 \mathrm{ohm}$ \\
Rotor leakage inductance & $0.0221 \mathrm{H}$ \\
Stator leakage inductance & $0.0221 \mathrm{H}$ \\
Mutual inductance & $0.4114 \mathrm{H}$ \\
Supply frequency & $50 \mathrm{~Hz}$ \\
Motor speed & $1500 \mathrm{r} . \mathrm{p} . \mathrm{m}$. \\
Supply voltage & $380 \mathrm{volts}$ \\
Inertia & $0.02 \mathrm{~kg} . \mathrm{m}^{2}$ \\
\hline
\end{tabular}

\section{A.2. List of Principle Symbols;}

$$
\mathbf{L}_{\boldsymbol{\sigma}}=\mathbf{L}_{\mathbf{S}}-\frac{\mathbf{L}_{\mathbf{m}}^{2}}{\mathbf{L}_{\mathbf{r}}} \quad \mathrm{T}_{\mathrm{r}}=\frac{\mathrm{L}_{\mathrm{r}}}{\mathrm{R}_{\mathrm{r}}}
$$$$
\sigma=1-\frac{\mathrm{L}_{\mathrm{m}}^{2}}{\mathrm{~L}_{\mathrm{s}} \mathrm{L}_{\mathrm{r}}}
$$

$V_{q s e}, V_{d s e} \quad \mathrm{q}^{\mathrm{e}}-\mathrm{d}^{\mathrm{e}}$-axis stator voltage

$I_{q s e}, I_{d s e} \quad \mathrm{q}^{\mathrm{e}}-\mathrm{d}^{\mathrm{e}}$-axis stator current

$\lambda_{q s e}, \lambda_{d s e} \quad \mathrm{q}^{\mathrm{e}}-\mathrm{d}^{\mathrm{e}}$-axis stator flux linkage

$R_{s}, R_{r} \quad$ stator and rotor resistances

$J, B \quad$ moment of inertia and viscous friction coefficients

$L_{s}, L_{r}, L_{m} \quad$ stator, rotor and mutual inductances $T_{e}, T_{L} \quad$ electromagnetic and load torque 